Geograficando, vol. 17, $\mathrm{n}^{\circ}$ 2, e103, noviembre 2021 - abril 2022. ISSN 2346-898X

Universidad Nacional de La Plata.

Facultad de Humanidades y Ciencias de la Educación.

Departamento de Geografía

\title{
Feria de los patos: el trabajo de las mujeres
}

\section{"Los patos" fair: women's work}

\author{
Camila Pilatti \\ camila.pilatti@mi.unc.edu.ar \\ Centro de Investigaciones de la Facultad de Filosofía \\ y Humanidades, Universidad Nacional de Córdoba, \\ Argentina
}

Recepción: 10 Marzo 2021

Aprobación: 25 Mayo 2021

Publicación: 01 Noviembre 2021

Cita sugerida: Pilatti, C. (2021). Feria de los patos: el trabajo de las mujeres. Geograficando, 17(2), e103. https://doi.org/10.24215/2346898Xe103
Resumen: En este artículo se propone un análisis del trabajo de las mujeres en una feria ambulante, gastronómica y primordialmente migrante de la ciudad de Córdoba: Feria de los Patos. Siguiendo la teoría de los circuitos de la economía urbana de Milton Santos (1977), y poniendo el foco en las feriantes, se analizan los productos ofertados, las estrategias de venta, la relación con los gobiernos, el capital disponible, los precios, el lucro, entre otras variables que intervienen en la configuración de este mercado. Se indagan las condiciones materiales y simbólicassociales que llevan a las feriantes a montar sus puestos en este espacio público, tomando en cuenta sus experiencias migrantes y su inserción en el mercado laboral cordobés. Este estudio se nutre de un registro etnográfico realizado entre los años 2018 y 2020, que consta de entrevistas, conversaciones informales y observación participante.

Palabras clave: Trabajo ferial, Circuito inferior, Trabajo femenino, Migrante.

Abstract: This article proposes an analysis of women's work in an itinerant, gastronomic and primarily migrant fair in the city of Córdoba: Feria de los Patos. Following Milton Santos' (1977) theory of urban economic circuits and focusing on the women fair vendors, the article analyzes the products offered, sales strategies, the relationship with governments, the available capital, prices, profit, among other variables involved in the configuration of this market. The material and symbolicsocial conditions that lead the fair vendors to set up their stalls in this public space are discussed, taking into account their migrant experiences and their insertion in the Cordoba labor market. This study is fed by an ethnographic record carried out between 2018 and 2020, consisting of interviews, informal conversations and participant observation.

Keywords: Fair work, Lower circuit, Female work, Migrant.

\section{INTRODUCCIÓN}

Este artículo se desprende de nuestro Trabajo Final de Licenciatura en Geografía titulado "La Feria de los Patos de la Ciudad de Córdoba. Economía urbana y apropiación del espacio público, 2018- 2020", presentado en diciembre de 2020. ${ }^{1}$ Nos proponemos analizar el trabajo de las mujeres en la Feria de los Patos, un mercado gastronómico e informal de la ciudad de Córdoba, a partir de la teoría de los circuitos de la economía urbana. Se trata de una teoría del geógrafo brasileño Milton Santos, planteada en sus 
libros Les Villes du Tiers Monde, de 1971, y The Shared Space: The Two Circuits of The Urban Economy in Underdeveloped Countries, de 1979. Para este análisis tomamos lecturas realizadas por otres autores con posterioridad (Grimm, 2011; Montenegro, 2011; Grimm \& Montenegro, 2017 y Silveira 2016; 2018). Nos enfocamos en las feriantes ya que la mayoría de los puestos son gestionados por mujeres (Miranda, 2017; 2018). ${ }^{2}$

\section{Metodología, ANTECedentes y MARCo Teórico}

Se trata de una investigación primordialmente cualitativa, que se nutre de distintas fuentes, primarias y secundarias, para la construcción de datos sobre la Feria. Artículos periodísticos, documentos oficiales, registros etnográficos e investigaciones (de diversas disciplinas) se articulan en esta investigación.

El trabajo de campo fue realizado entre los años 2018 y 2020, y se condensa en lo que llamamos "cuaderno de campo" (C.C.). En este se aglutinan los registros surgidos de la observación participante de la Feria, las entrevistas en profundidad y las conversaciones informales realizadas a feriantes y visitantes (Achilli et al., 2005). Vale mencionar que entre nuestres informantes hay mujeres y hombres, feriantes y visitantes.

Para la caracterización de la Feria, fueron centrales las investigaciones de Flores, Huerta, Lerda \& López Ramírez (2017), Farías \& Tallarico (2014) y Miranda (2017; 2018), ya que, desde distintos campos disciplinares, nos aportaron datos sobre esta feria en particular. Específicamente, Miranda (2017; 2018) nos alertó sobre la preeminencia de mujeres a cargo de los puestos, lo que nos llevó a enfocar el estudio en las feriantes. Para comprender la inserción de este mercado en el barrio Alberdi y en la ciudad de Córdoba tomamos los trabajos de Abraham \& Suyai (2016), Capdevielle (2014) y Pantano \& Rodigou (2018). El trabajo de Busso (2011) nos aportó herramientas para pensar las ferias como espacios históricos de intercambios, de interacción social, de encuentros y socialización. Estos intercambios son no sólo de mercancías sino también de historias, de vivencias, códigos, costumbres, informaciones. En tanto, Gómez \& Sánchez (2016) nos acercan información relevante sobre los procesos migratorios de Perú hacia Córdoba que también impactan en esta feria.

Para analizar el trabajo de las feriantes atendiendo a los circuitos de la economía urbana, tomamos las lecturas de Grimm (2011), Montenegro (2011), Grimm \& Montenegro (2017) y Silveira (2016; 2018), y un breve artículo de Santos publicado en el Boletín Paulista de Geografía (1977). María Lura Silveira (2018) retoma la propuesta teórica de Santos para indicar que la economía urbana está conformada por dos sub-sistemas que, con diversos grados de tecnología, capital y organización, se interrelacionan, complementan y compiten. Mientras el circuito superior presenta elevados niveles de organización, de capital y de tecnología que, muchas veces con apoyo del Estado, propicia el desarrollo de actividades económicas con alta rentabilidad, el inferior se orienta más a la sobrevivencia y dispone de niveles considerablemente menores de organización, capital y tecnología (Silveira, 2016, p. 88).

En el circuito inferior la principal tecnología suele vincularse con el trabajo intensivo. En cambio, en el superior se asocia más a la disponibilidad de grandes capitales que se invierten en diversas áreas como tecnología y publicidad (Grimm, 2011, p. 123). También difieren en su vinculación con los gobiernos (locales y nacionales) y con el mercado externo: el superior mantiene estrechos vínculos con el exterior y se nutre del capital fijo y de las medidas que los gobiernos implementan buscando atraer inversiones; en cambio, el inferior puede prescindir de todo esto. Este último se caracteriza por entablar relaciones directas y personales con la clientela, por la negociación de los precios in situ, por el elevado margen de lucro por unidad y por el otorgamiento de créditos no bancarizados sino interpersonales. En este circuito los puestos de trabajo son más numerosos, generalmente la organización es más rudimentaria y son poco frecuentes los salarios fijos. En tanto, en el circuito superior la oferta laboral generalmente establece salarios fijos, su organización es burocrática y la demanda de trabajadores es considerablemente menor que en el otro circuito. En el superior priman las relaciones impersonales, muchas veces a través de documentos u otros dispositivos; los precios 
habitualmente son fijos, los créditos provienen de entidades bancarias o del Estado, el margen de lucro es elevado en grandes cantidades y reducido por unidad (salvo cuando se trata de bienes de lujo) y las existencias (stock) disponibles son cuantiosas o de alta calidad (Santos, 1977, pp. 43-49).

Por su parte, Quiroga \& Gago (2018) proponen una mirada feminista de la economía urbana. Explican que las formas urbanas, signadas por la segregación, asocian el espacio público a lo productivo y masculino, en tanto que la reproducción corresponde a las mujeres y es relegada al ámbito privado. Empero, actualmente las mujeres también se encargan de las tareas de producción y no por ello merma su participación en las tareas reproductivas. ${ }^{3}$ Para romper el enclaustramiento de las condiciones de reproducción confinadas al ámbito de lo privado y asignadas a las mujeres $(2018$, p. 223), sostienen que "la feminización de la política en lo urbano plantea con fuerte acento una expansión de la racionalidad doméstica como algo ya no privado, sino como una dimensión propicia para la construcción colectiva de lo común” (2018, p. 325). Nos alertan sobre la opresión y la centralidad de las mujeres en la reproducción del sistema capitalista. Además, nos aportan herramientas para problematizar la relación público-privado y así identificar otras formas de organizar la ciudad, signadas no sólo por la racionalidad económica.

\section{La Feria en el barrio}

La Feria de los Patos, que data aproximadamente del año 2007, se realiza todos los domingos en un espacio público de la ciudad de Córdoba llamado la Isla de los Patos (Flores et al., 2017; Miranda, 2017, 2018; y Farías \& Tallarico, 2014). ${ }^{4}$ Se trata de una isla parquizada de 1.6 hectáreas, ubicada en el cauce del río Suquía, que atraviesa la ciudad de noroeste a este. Se accede a ella a través de dos puentes, uno desde barrio Alberdi y el otro desde barrio Providencia. Llegan desde diferentes barrios de la ciudad feriantes y visitantes para, entre otras cosas, degustar platos típicos de Perú (anticuchos, papa rellena, platos combinados, papas a la huancaína, picarones, mazamorra, marcianos, entre otros), adquirir productos de aquel país, aprovechar el espacio verde y encontrarse con compatriotas. Este mercado se monta con sombrillas, gazebos, mesas, sillas, anafes, conservadoras, tachos de pintura, entre otros elementos que propician el traslado, conservación y comercialización de los productos allí ofertados. El número de puestos oscila entre 20 y 50 , aproximadamente. En la siguiente fotografía (Figura 1) se muestran dos puestos orientados principalmente a la venta de gaseosas, jugos de frutas, chicha (bebida hecha a base de maíz) y marcianos (jugo de frutas congelado). Allí podemos observar a algunes feriantes junto a los distintos elementos que trasladan para montar sus puestos.

FIGURA 1

Puestos de bebidas - Registro propio

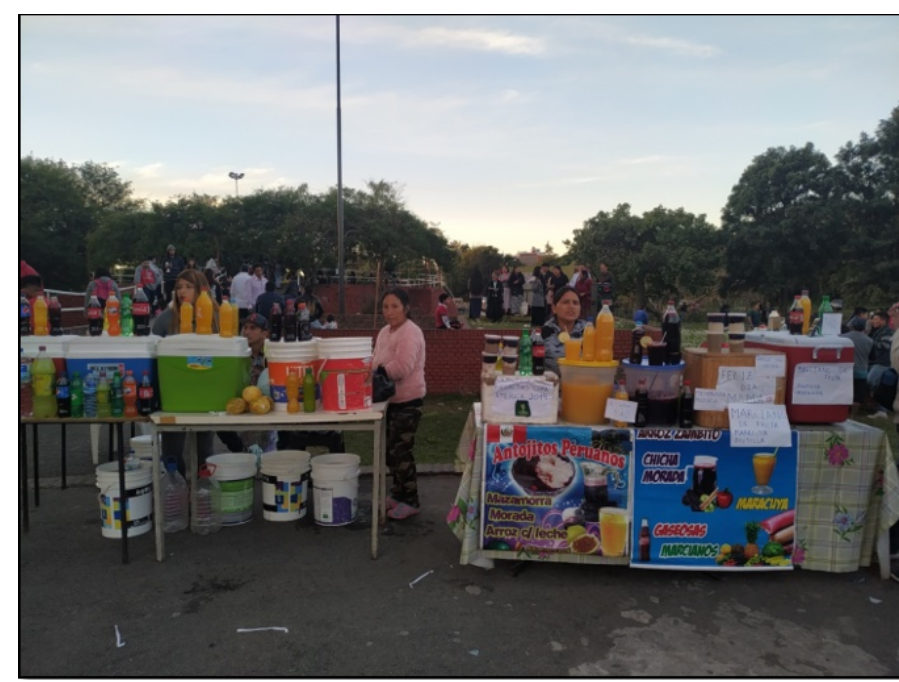

La oferta consiste principalmente en comidas y productos que se vinculan con Perú. En el caso de las comidas, suele tratarse de recetas peruanas, en tanto los demás productos suelen ser importados de aquel país u otros limítrofes (y a su vez, se emplean en las recetas antes mencionadas). No obstante, la 
preeminencia peruana no debe confundirse con exclusividad, pues habitualmente concurren personas de diferentes nacionalidades, en carácter de feriantes y visitantes. Asimismo, la oferta excede a la gastronomía peruana (hamburguesas, panes, arepas, papas fritas, entre otros). A partir de esto, entendemos que tomar en cuenta tanto la presencia peruana como la de otras nacionalidades aporta a la comprensión de la Feria de los Patos, de quienes la visitan y de quienes la montan cada semana: gran parte de la población que asiste comparte experiencias vinculadas a procesos migratorios, mas no sólo del Perú. Otro dato relevante es que entre les feriantes priman las mujeres.

$\mathrm{Al}$ respecto del surgimiento de la Feria, Flores et al. (2017), Miranda (2017; 2018) y Farías y Tallarico (2014) identifican su inicio entre 2007 y 2008 y, al igual que les entrevistades, coinciden en que comenzó con unos pocos puestos de comidas peruanas, que progresivamente se fueron multiplicando y diversificando. En nuestro trabajo de campo llegamos a saber que son varios los puestos que se autoproclaman pioneros. Esto nos lleva a pensar que la antigüedad es valorada por las feriantes, les otorga algún tipo de legitimidad. Así, ante debates en torno a la ocupación del espacio, el tipo de productos ofertados, ${ }^{5}$ la relación con la municipalidad, suelen emerger las referencias a la antigüedad en la Feria.

A fin de aproximar a les lectores al espacio estudiado, presentamos algunos datos sobre la ciudad de Córdoba y el barrio Alberdi, que entendemos aportan a la comprensión de la Feria.

Alberdi, desde principios del siglo XX, se caracteriza por la presencia estudiantil y obrera, que lo colocó como sede de la Reforma Universitaria de 1918, el Cordobazo y, más recientemente, la toma de la ex Cervecería Córdoba. ${ }^{6}$ En el barrio, el avance del modelo neoliberal fue quitando protagonismo al sector obrero mas no al estudiantil. Así, actualmente se pueden encontrar instituciones educativas de todos los niveles (inicial, medio y superior). Otro dato que aporta a la comprensión del vínculo entre la Feria y el barrio se refiere a la radicación de migrantes peruanes que, con fluctuaciones, se registra desde finales del siglo XX (Abraham \& Suyai, 2016; Capdevielle, 2014; Pantano \& Rodigou, 2018).

Siguiendo a Capdevielle (2014), entendemos que luego de la crisis del 2001 se abre paso un nuevo modelo económico, orientado a estimular el mercado interno. El aumento del dólar respecto del peso argentino colaboró con la recuperación del sector industrial (fuertemente deteriorado durante el neoliberalismo) y del sector agroexportador, que además se vio favorecido por el alza de los precios internacionales de algunos commodities agrícolas (por ejemplo, la soja). En ese contexto, Alberdi devino locus de inversión del capital inmobiliario (Pantano \& Rodigou, 2018), visto que la adquisición de propiedades inmuebles se presentaba como una alternativa de ahorro a futuro para algunos sectores de la economía que estaban en ascenso (agroexportador e industrial). Vale mencionar que este desarrollo inmobiliario fue propiciado por el cambio de modelo económico y por renovados vínculos entre los grupos empresariales ${ }^{7}$ y el Estado municipal (Capdevielle, 2014, p. 6). "Este último facilitó el desarrollo de importantes emprendimientos inmobiliarios a través de múltiples acciones y omisiones" (Capdevielle, 2014, p. 6). Así, el barrio experimentó "una acelerada intervención en la morfología y en las formas de vida barrial, algo que en la actualidad, es un eje central a la hora de pensar las diferentes tensiones y disputas barriales" (Pantano \& Rodigou, 2018, p. 72). En el siguiente mapa se muestran los barrios próximos a la Isla de los Patos. Queremos destacar cuán cerca del centro de la ciudad se monta la Feria. 
FIGURA 2

Barrios aledaños a la Isla de los Patos - Elaboración propia

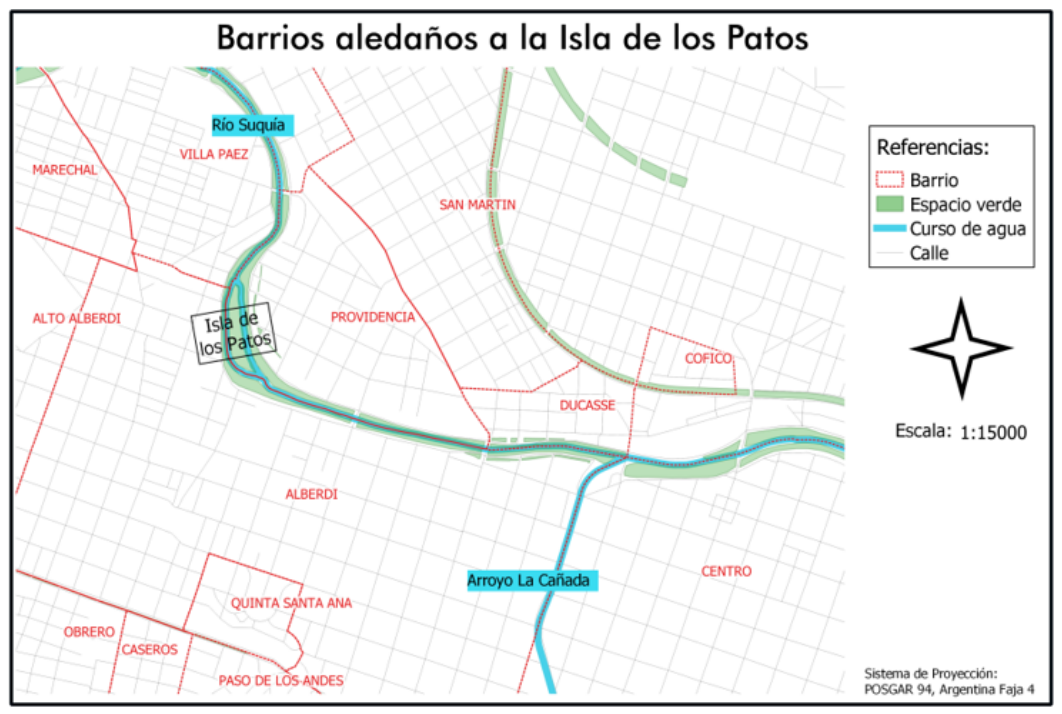

Volviendo a la presencia peruana en el barrio, tomamos la propuesta de Gómez \& Sánchez (2016), que distinguen dos períodos de migración peruana hacia Córdoba: el primero a partir de la década de 1960, motivado por la formación profesional (venían a estudiar en la universidad); y el segundo desde 1980, vinculado con búsquedas laborales (que la mayoría de las veces se desarrollan en un marco informal). Mientras les migrantes recientes tienden a agruparse en zonas específicas, les más antigües se han ido dispersando con el paso del tiempo. Asimismo, les peruanes disperses tienen una mayor diversificación en cuanto a la estructura ocupacional y una mejor posición socioeconómica que les agrupades, principalmente los hombres. Sólo aquellos que residen hace menos tiempo en la ciudad suelen dedicarse a la construcción; en cambio, las mujeres dispersas y agrupadas presentan una situación socioeconómica más precaria que los hombres (trabajan la mayoría de las veces como empleadas domésticas) (Gómez \& Sánchez, 2016, p. 18).

Como indicamos anteriormente, no abordamos lo peruano como diacrítico de este mercado, visto que no consideramos que la identificación nacional sea determinante en esta feria. Empero, entendemos que conocer la población que tiene mayor presencia, que le dio origen y que al día de hoy la sigue dinamizando puede aportar a la comprensión de los distintos intercambios que allí se conjugan. Es decir, conocer los procesos migratorios que atañen a la mayor parte de les feriantes abona al estudio de la Feria como parte del circuito de la economía urbana. Además, nos aporta información relevante sobre la disparidad de género que en el mundo laboral experimenta esta población, dado que la mayoría de los puestos son gestionados por mujeres.

\section{LA Feria en el CIRCUITo INFERIOR}

La teoría de la economía urbana de Santos (1977) nos aporta herramientas para pensar la Feria de los Patos en tanto mercado que dispone de escaso capital, reducidos niveles de rentabilidad (en comparación con las grandes firmas) y una organización mayormente rudimentaria y carente de documentos formales que regulen su funcionamiento. Si bien hay quienes promueven que se tramite la personaría jurídica de la Feria, otras feriantes prefieren no involucrarse formalmente (Pilatti, 2020). La posición de la Feria en relación con el gobierno municipal es intrincada. Por un lado, no se atiene a las normativas municipales que regulan las actividades feriales ni gastronómicas y no cuenta con apoyo y reconocimiento estatal. Por el otro, hay registros de algunos diálogos con el municipio, en los que este ha respondido a demandas de las feriantes: problemas con el alumbrado público, con los puentes o con los cestos de basura. Otra forma de reconocimiento es la instalación de tres placas conmemorativas dedicadas a la "Colectividad Peruana", que se ubican en la zona donde se monta la Feria y datan del año 2015.

Al margen de su compleja vinculación con los gobiernos, entendemos que aquí se conjugan otras formas de institucionalidad que se asocian con la permanencia de la Feria. Por ejemplo, cada domingo quienes participan realizan un aporte monetario para costear la limpieza del predio, frecuentemente realizan 
reuniones de todes les que asistieron ese día para resolver situaciones específicas y, en algunos períodos, han conformado una Junta Directiva. ${ }^{8}$ Esta consta de varios cargos ocupados por feriantes, carece de documentación que regule su funcionamiento y no cuenta con el apoyo de todes les feriantes. Hasta la fecha, no se han logrado acuerdos sobre la incorporación de nuevos puestos. Hay quienes promueven abiertamente la expansión de la Feria, pues entienden que al incorporarse nuevos puestos atraerían más clientes. En cambio, otres solicitan la regulación de la oferta gastronómica, para evitar la competencia entre feriantes. Desde esa perspectiva, procuran que se respeten sus ubicaciones y que sólo se agreguen puestos si su oferta es novedosa. De ese modo evitarían la competencia con puestos semejantes y que sus ausencias eventuales produzcan la pérdida de sus emplazamientos (Pilatti, 2020, p. 86).

Las feriantes no cuentan con salarios fijos y su trato con la clientela es directo y personal. Los precios son relativamente fijos, pues ante pocas ventas o al final del día todo se vende más barato, para evitar que se eche a perder (Pilatti, 2020). José Miranda $(2017 ; 2018)$ analiza los intercambios en la Feria y describe un entramado de relaciones que exceden lo puramente comercial: se busca "llamar la atención" y "enganchar" a les comensales, con el "buen trato" como una premisa central para tal fin. Habitualmente, los pagos se realizan luego de consumidos los productos. Los puestos que cuentan con vajilla reutilizable, como la que se muestra en la Figura 3, invitan a sus comensales a instalarse en cualquier parte de la Isla y, al momento de realizar el pago, devolver la vajilla.

FIGURA 3

Plato de seco con frijoles - Registro propio

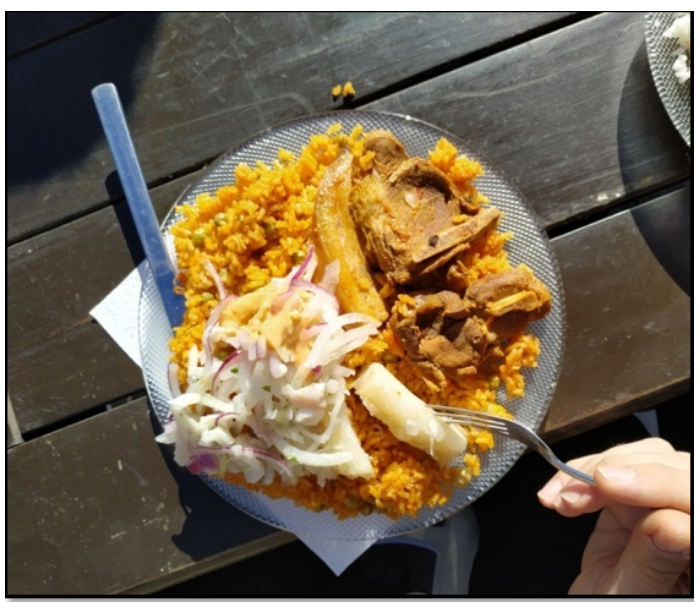

En la Feria se destaca el trabajo intensivo: sea en la preparación de productos comestibles, en el proceso de importación o en la trabajosa atención a les clientes. La preparación de los platos implica logística pues, además del traslado, la conservación de la temperatura y su presentación, se debe gestionar la compra de insumos con antelación. Las feriantes que se desempeñan en otros trabajos durante la semana suelen encargar a familiares o amistades las compras, o bien las realizan los sábados por la mañana al concluir su jornada laboral en relación de dependencia. ${ }^{9}$ En tanto, la importación se refiere a la venta de productos que se comercializan en Perú: para traerlos, las feriantes viajan a este país, Bolivia o Chile, o bien encargan mercadería a familiares y amistades que vienen desde el exterior (Pilatti, 2020). En resumen, feriar implica varias tareas: gestiones y preparaciones previas, traslado del puesto (mesas, sillas, sombrillas, etc.), su montaje y desmontaje, y la venta y atención, que supone diferentes estrategias para "enganchar" y "llamar la atención" de clientes (Miranda, 2017; 2018).

La Feria, desde sus inicios en el año 2007, ha ido creciendo progresivamente, incorporando nuevos puestos y diversificando su oferta (Pilatti, 2020). Al tiempo que se incorporan nuevas feriantes, otras dejan su puesto mientras que otras cambian de rubro, y por ejemplo, pasan de vender platos completos a vender únicamente postres. La expansión de la Feria, en cantidad de puestos y diversificación de la oferta, nos hace suponer que existe y se multiplica un sector de la población de Córdoba que encuentra en este mercado una fuente de trabajo y también una posibilidad de consumo (Montenegro, 2011), pues probablemente le resulte demasiado costoso consumir fuera de ella. En relación con ello, creemos importante mencionar el 
surgimiento de otras ferias en las inmediaciones que, por su proximidad, podrían representar algún tipo de competencia. $^{10}$

Esto último nos lleva a remarcar la especificidad de esta feria que, sin ser excluyente, es preeminentemente peruana. Los productos ofertados (sean caseros o industrializados), la disposición de los puestos (diversidad de sabores y sazones en el mismo mercado), el trato con la clientela y las celebraciones ${ }^{11}$ son algunos elementos que les entrevistades mencionaron como característicos de la Feria.

Entendemos que el desarrollo de este mercado en un espacio público (la categoría "espacio público" abre numerosos debates; en esta oportunidad nos referimos únicamente al acceso irrestricto y a la gestión estatal) supone la posibilidad de percibir ingresos por el montaje del puesto sin necesidad de pagar un alquiler ni contraer ningún contrato de permanencia. No obstante, debemos considerar que los productos ofertados y los diversos elementos que conforman el puesto (sombrillas, sillas, mesas, tachos, quemadores, heladera, etc.) sí implican una inversión para las feriantes, además del aporte que realizan para la limpieza (que sólo pagan cuando montan su puesto). Así como tienen muy presente la asistencia que, sin ser obligatoria, corre por cuenta de cada feriante. Es sabido que cuando se ausentan varios domingos consecutivos ponen en riesgo su localización en la Feria (Pilatti, 2020).

La realización de la Feria en un espacio público también se vincula con la concurrencia de visitantes. Nuestres interlocutores indicaron que se trata de "un sitio de encuentro para compartir y comer" (C.C. 12/01/2020), que es característico por "la comida. Venir a comer, el encuentro con amigos, paseo" (C.C. 14/04/2019), "porque son todos casi peruanos, puro peruano. Hay comidas típicas" (C.C. 04/01/2020), "encontrarás las cosas nuestras, las cosas, los sabores, tal vez no todos" (C.C. 10/01/2020). Estos testimonios nos invitan a pensar que el público que escoge esta feria encuentra en ella algo más que productos alimenticios. De allí que algunas personas permanezcan en el predio aun después de haber comido y que otras tantas asistan aun sin consumir nada. Asimismo, cuando se realizan celebraciones en el marco de la Feria aumentan la concurrencia y la permanencia de visitantes, que son potenciales consumidores.

$\mathrm{Al}$ respecto de las fluctuaciones, también notamos que el estado del tiempo influye en la cantidad y conformación de los puestos. Así, ante días lluviosos o ventosos encontramos una versión reducida de la Feria, pues se monta con lo mínimo e indispensable y el volumen de ventas es menor. Aun con mal tiempo la Feria no se suspende, dado que los platos fueron preparados con antelación y de no venderse ese día se echarían a perder (la mayoría de las feriantes participan únicamente en este espacio ferial). Además, las ventas del domingo representan un ingreso importante para ellas. Hay quienes perciben esta venta como su principal ingreso, mientras que para otras es un complemento de los trabajos que realizan durante la semana.

\section{MuJERES, MIGRANTES Y FERIANTES}

Cada domingo las feriantes arman y desarman sus puestos al margen de cualquier legislación que proteja a les trabajadores: obra social, jubilación, vacaciones pagas, etc. Ante esto, nos preguntamos ¿cómo es la vida de aquellas personas que encuentran en el trabajo ferial la posibilidad de sustentarse económicamente?

Nuestro trabajo de campo no nos permitió conocer datos numéricos de la economía de las feriantes, que se mostraban reticentes a responder preguntas sobre ese tema. No obstante, sin ahondar en montos y datos personales precisos, llegamos a conocer aspectos relevantes de su economía. Casi todos los puestos son gestionados por mujeres: ellas administran el dinero y la comida y, en ocasiones, son asistidas en tareas específicas por familiares o amigues, de cualquier género (llamar clientes, limpiar la mesa, cuidar el puesto, entre otras). De estas mujeres, la mayoría trabaja como empleada doméstica: algunas "cama adentro" y otras sólo durante el día. En la misma dirección, un estudio de Gómez y Sánchez indica que, para el año 2016, más del $75 \%$ de las mujeres migrantes peruanas que residían en Córdoba trabajaban como empleadas domésticas; y del total de las mujeres, menos del $15 \%$ contaba con obra social y aportes jubilatorios (2016, pp. 14-15). Esos datos podrían indicar que los empleos en "casas de familia" muchas veces no se atienen a los regímenes 
de trabajo oficiales. Además, no todas han tramitado la nacionalidad o la residencia en la Argentina, lo que implica una limitación a la hora de buscar empleos registrados y viviendas para alquilar. La precariedad de su inserción en el mundo laboral se complejiza aún más si ellas son el sostén principal (cuando no el único) de la familia, lo que es bastante frecuente. Muchas de ellas se refirieron a sí mismas como "madre soltera”, ya que afrontan solas los costos del cuidado de sus hijes, pues se trata de familias monoparentales. Algunas veces su familia reside en Córdoba y otras deben enviar dinero a Perú para mantener a hijes u otres familiares.

Queremos destacar que muchas veces el trabajo ferial marcado por un discurso que asocia la libertad al cuentapropismo implica también dependencias, ataduras y contradicciones, como en tantos otros ámbitos laborales (Busso, 2010, p. 121). Entendemos que en la Feria lo que aglutina a las feriantes es la necesidad económica asociada a la dificultad de acceder a un "trabajo digno" (nos referimos a un trabajo bien remunerado que permita a las personas vivir en condiciones decentes, cubriendo sus necesidades básicas y gozando de todos los derechos laborales que rigen en nuestro país). Al respecto, Milton Santos observaba en 1977:

La presencia de una masa poblacional con salarios muy bajos, dependiendo de trabajo ocasional para vivir, al lado de una minoría con altos salarios, crea en la sociedad urbana una distinción entre los que tienen permanente acceso a los bienes y servicios ofrecidos y los que, aun presentando necesidades similares, no pueden satisfacerlas. Esto crea al mismo tiempo diferencias cualitativas y cuantitativas de consumo. Estas diferencias son ambas, causa y efecto de la existencia, esto es, de la creación o manutención, en estas ciudades, de dos sistemas de flujo que afectan la fabricación, la distribución y el consumo de bienes y servicios. Uno de estos dos sistemas de flujo es el resultado directo de la modernización y se refiere a actividades creadas para servir al progreso tecnológico y a la población que de él se beneficia. El otro es también un resultado de la modernización, pero un resultado indirecto, visto que concierne a aquellos individuos que sólo parcialmente se benefician, o absolutamente no se benefician, del reciente progreso técnico y de las ventajas a él ligadas. (Santos, 1977, p. 37) ${ }^{12}$

Esa masa poblacional con bajos salarios, que en el caso de la Feria es mayormente migrante y femenina, va trazando diferentes estrategias de supervivencia. Por ejemplo, al trabajar como empleadas domésticas pueden ahorrar gastos de alquiler si optan por vivir en la casa de sus patrones (modalidad "cama adentro"). En cambio, si optan por alquilar, pueden arrendar una habitación en una pensión en vez de una casa o departamento que acarrea otros gastos (impuestos y servicios). Mientras unas arriendan habitaciones o departamentos en Alberdi u otros barrios aledaños (pericentrales), otras prefieren alejarse del centro de la ciudad con tal de acceder a una vivienda propia y dejar de destinar parte de su salario al pago de alquileres.

Las estrategias habitacionales se conectan con la participación en la Feria, pues las que residen lejos del centro y no poseen movilidad propia se ven desfavorecidas al tener que afrontar elevados costos en transporte. Según nos comentaron las feriantes, el costo del taxi o flete es tan elevado que muchas veces deja de ser rentable montar el puesto para las que no disponen de medios de transporte propios. De allí que muchas prefieran arrendar habitaciones o departamentos pequeños próximos a la Isla de los Patos (en Alberdi, San Martín, Providencia, Alto Alberdi, etc.), pues así pueden trasladar a pie todo lo necesario para montar el puesto, generalmente con ayuda de algún tipo de carro con ruedas. También nos comentaron que hay quienes ofrecen los domingos, a sus compatriotas, servicios de fletes a menor costo.

Con todo esto procuramos reflexionar en torno al peso que puede llegar a tener la dimensión económica en la decisión de montar un puesto en la Feria de los Patos. Es decir, intentamos despegarnos momentáneamente de la idea de la Feria como lugar de encuentro para preguntarnos por las implicancias económicas que puede tener este mercado para un sector de la población cordobesa, que es principalmente migrante y femenino. En ese sentido, Santos (1975) indica que "la preocupación por la supervivencia supera a la preocupación del lucro como elemento funcional de la actividad” (citado en Silveira, 2018, p. 236).

En contrapartida, consideramos que no basta con describir las condiciones materiales de las feriantes para comprender la existencia y permanencia de la Feria. Pues entendemos que esa "preocupación por la subsistencia" se enlaza con diferentes prácticas desplegadas por las feriantes para favorecer el desarrollo de la Feria. Por ejemplo, al prestarse dinero y facilitarse el cambio, cuidarse mutuamente los puestos, ayudarse o 
acompañarse en las largas horas que pasan allí. Así se van forjando vínculos que son, simultáneamente, laborales y simbólicos/representacionales. Por eso, pensamos que la decisión de montar un puesto no se explica solamente por sus necesidades económicas, visto que la elección de hacerlo en esta feria se conecta con aspectos más subjetivos: es la que más frecuentan y conocen, cuentan con apoyo de otras feriantes, saben preparar comida peruana y, en palabras de una feriante: "hay melancolía de los que han venido e iniciado su vida acá" [Barrio Alberdi] (C.C., 12/01/2020). Ahora bien, esa conexión de la Feria con el barrio no borra su dimensión económica.

\section{Conclusiones}

El espacio público de la Isla de los Patos alberga un mercado, donde numerosos actores de escaso poder adquisitivo producen y comercializan bienes y servicios accesibles para aquellos estratos de la población cuyas necesidades difícilmente encuentran respuestas en el circuito superior (Silveira, 2018, p. 239). Su carácter público y su localización (barrio Alberdi y próximo al centro) propician el desarrollo de la Feria, que es un espacio de consumo y trabajo para los sectores menos capitalizados. Al mismo tiempo, la cotidianeidad compartida con demás actores desprovistos de poder configura una interdependencia que favorece el trabajo conjunto para alcanzar resultados colectivos (Silveira, 2018, p. 241). El ambiente "familiar", muy vinculado por les entrevistades a la presencia infantil (C.C.), y la higiene del predio, que favorecen la concurrencia a este mercado, se construyen colectivamente velando por la seguridad y costeando los gastos de limpieza. Asimismo, la colaboración entre feriantes que se prestan dinero y se cuidan los puestos aporta a la buena atención, que también atrae clientela.

Finalmente, nuestra experiencia en este espacio nos conecta con una realidad social marcada por la xenofobia y la segregación socio-espacial, al tiempo que presenta otras formas posibles de vincularse, de producir y de intercambiar. Nos interpela, resalta las desigualdades, las injusticias y los prejuicios. Esta feria, que es una fuente de ingresos y un lugar de encuentro para la población peruana de Córdoba, se conjuga en un espacio público y reafirma la importancia de este tipo de espacios para el ejercicio de ciudadanías más democráticas, que contemplen y respeten la diversidad. La Feria aporta visibilidad a un sector de nuestra sociedad marcado por la discriminación y reivindica los tratos interpersonales y una forma de organización colaborativa y solidaria.

En esa línea, Quiroga \& Gago (2018) indican que las organizaciones sociales y los movimientos van tejiendo "estrategias de sobrevivencia" que aportan otras formas de hacer la ciudad, fortaleciendo los procesos colectivos de socialización de lo reproductivo y la construcción de bienes comunes urbanos, capaces de resolver necesidades y producir bienestar colectivo sin una mediación necesaria y exclusiva del mercado y del Estado (2018, p. 308). En ese sentido, consideramos que la preeminencia de mujeres feriantes no se explica sólo por su inserción precarizada en el mercado laboral, sino también por la expansión de la racionalidad doméstica que propicia la construcción colectiva de lo común (2018, p. 325).

\section{REFERENCIAS}

Abraham, E. \& Suyai Pereyra, A. (2016). Configuraciones estratégicas en torno al espacio. Caso: Barrio Güemes y Alberdi. En C. La Serna (Ed.), Estado, politica pública y acción colectiva: praxis emergentes y debates necesarios en la construcción de la democracia (pp. 635-645). Córdoba: Universidad Nacional de Córdoba. Recuperado de h ttp://hdl.handle.net/11086/5943

Achilli, E. \& otros (2005). Investigar en antropología social: los desafios de transmitir un oficio. Rosario: Editorial Laborde Libros. 
Busso, M. (2011). Las ferias comerciales: también un espacio de trabajo y socialización. Aportes para su estudio. Trabajo y Sociedad. Sociología del trabajo - Estudios culturales - Narrativas sociológicas y literarias, XV(16). Recuperado de https://www.unse.edu.ar/trabajoysociedad

Capdevielle, J. (2014). Estrategias habitacionales de resistencia: La lucha de la multisectorial “Defendamos Alberdi” en la ciudad de Córdoba, Argentina. En el 6to Seminario Internacional de Investigación en Urbanismo. BarcelonaBogotá.

Farías, V. \& Tallarico, M. (2014). La Isla de los Patos: "Un lugar que lo hemos tomado como nuestro" (tesina de grado). Escuela de Trabajo Social de la Facultad de Derecho y Ciencias Sociales, Universidad Nacional de Córdoba, Argentina.

Flores, C. E., Huerta, M. G., Lerda, L. del R., \& López Ramírez, R. (2017). Territorios chejes. La co-construcción de un espacio común alternativo en la Feria Isla de los Patos (tesina de grado). Escuela de Trabajo Social de la Facultad de Derecho y Ciencias Sociales, Universidad Nacional de Córdoba, Argentina.

Gómez, P. \& Sánchez Soria, D. (2016). Concentración, dispersión y características sociodemográficas en la incorporación espacial de la migración peruana en la Ciudad de Córdoba, Argentina. Revista Población y Salud en Mesoamérica, 14(1), pp. 1-22.

Grimm, F. (2011). Trajetória epistemologica de Milton Santos: uma leitura a partir da centralidade da técnica, dos diálogos com a economia política e da cidadania como práxis (Tesis doctoral). Brasil: Departamento de Geografía de la Facultad de Filosofía, Letras y Ciencias Humanas, Universidad de São Paulo.

Grimm, F. \& Montenegro, M. R. (2017). Used Territory: Ontology and praxis in the thought of Milton Santos [Territorio usado: ontología y praxis a través de Milton Santos]. En Symposium Commentaries on "The Active Role of Geography: A Manifesto. Traducido por L. Melgaço. y T. Clarke. Symposium Commentaries on "The Active Role of Geography: A Manifesto". Londres: Antipode Foundation (publicación original en portugués: año 2000). Recuperado de https://antipodeonline.org/wp-content/uploads/2017/01/2_grimm-and-montene gro_used-territory1.pdf

Miranda Pérez., J. (2017). Enganchar, llamar la atención y acumular en una feria de comidas en Córdoba. Revista del Museo de Antropologia, 10. Recuperado de http://revistas.unc.edu.ar/index.php/antropologia/index

Miranda Pérez., J. (2018). Junto, tupido y abundante: Economias feriantes y (contra)organización política. Buenos Aires: Antropofagia.

Montenegro, M. R. (2011). A teoria dos circuitos da economia urbana de Milton Santos: de seu surgimento à sua atualização [La teoria de la economia urbana de Milton Santos: de su surgimento a su actualización]. Revista Geográfica Venezolana, 53, pp 147-164.

Pantano, J. \& Rodigou C. J. (2018). Las tensiones en el paisaje de Alberdi. El barrio de la Reforma hoy. Cardinalis: Revista del Departamento de Geografia, 6(10), pp. 70-98.

Pilatti, C. (2020). La feria de los Patos de la Ciudad de Córdoba. Economia urbana y apropiación del espacio público, 2018- 2020 (trabajo final de licenciatura). Departamento de Geografía, Universidad Nacional de Córdoba.

Quiroga Díaz, N. \& Gago, V. (2018). Los comunes en la reinvención de la ciudad. Una mirada feminista de la economía urbana. En J. L. Coraggio y R. Muñoz (directores), Economía de las ciudades de América Latina hoy I: enfoques multidisciplinarios (pp. 307-330). Los Polvorines: Universidad Nacional de General Sarmiento.

Santos, M. (1977). Desenvolvimento econômico e Urbanização em Países subdesenvolvidos: os dois sistemas de fluxo da economia urbana e suas implicações espaciais [Desarrollo económico y Urbanización en Países subdesarrollados: los dos sistemas de flujo de la economía urbana y sus implicancias espaciales]. Boletim Paulista de Geografia, 53, pp. 35-59.

Silveira, M. (2016). Constitución de los circuitos de la economía urbana en la globalización. Revista Universitaria de Geografia, 25(2), pp. 79-102.

Silveira, M. (2018). Economía política y orden espacial: circuitos de la economía urbana. En J. L. Coraggio \& R. Muñoz (directores), Economia de las ciudades de América Latina hoy I: enfoques multidisciplinarios (pp. 213-250). Los Polvorines: Universidad Nacional de General Sarmiento. 


\section{Notas}

1 Dirigida por Julieta Capdevielle y codirigida por Miriam Abate Daga, de la Facultad de Filosofía y Humanidades, de la Universidad Nacional de Córdoba.

2 De aquí en adelante, para facilitar la lectura, nos referimos a esta feria en particular con mayúscula inicial: la Feria. Procurando eludir el uso sexista de la lengua, optamos por emplear pronombres neutros cuando las personas mencionadas no se identifican todas con el mismo género. Y las generalizaciones no se realizan en masculino, sino para mujeres con "a", para varones con "o" y para grupos mixtos con "e". También se emplea la "e" para identidades no binarias (masculino-femenino). Entendemos el uso inclusivo de la lengua como una práctica que favorece el respeto a la diversidad sexo-genérica y combate el machismo de nuestra lengua. Para ampliar sobre el tema, recomendamos "Consideraciones sobre el uso inclusivo de la lengua" de la "Comisión uso inclusivo de la lengua" de la FFyH-UNC, que reflexiona en torno a distintas corrientes que se opusieron al uso sexista de la lengua, para proponer un uso de ella que desestabilice las convenciones lingüísticas mediante las cuales versiones recalcitrantes del género perviven y se actualizan. Disponible en https://ffyh.unc.edu.ar/alfilo/consideraciones-sobre-el-uso-inclusivo-de-la-lengua/

3 Para comprender las implicancias de la desigual división del trabajo por géneros, se recomienda Brosio, M. (2016). Introducción a la medición de la brecha salarial por género y sus determinantes. - Economia Femini(s)ta. Disponible en https://economiafeminita.com/introduccion-a-la-medicion-de-la-brecha-salarial-por-genero-y-sus-determinantes/

4 Debido a la pandemia de covid-19 entre 2020 y 2021, ha sufrido algunos cambios. Durante los primeros meses la Feria se suspendió pero luego volvió a montarse en diferentes espacios públicos próximos a la Isla de los Patos. Desde entonces su localización varía entre una calle próxima a la Isla, la Costanera (márgenes del río frente a la Isla) y su lugar habitual: la Isla de los Patos.

5 Por ejemplo, Miranda (2017) relata: "En una ocasión una encargada de un puesto de postres trajo una parrilla de anticuchos con la intención de ampliar su negocio. Esto desató una ola de comentarios por parte de sus compañeras feriantes, que se quejaban a espaldas de ella por ambiciosa y desconsiderada, ya que en su afán de abarcar de más las iba a llenar de humo y ensuciar. Al poco tiempo ella dejó de llevar la parrilla de anticuchos” (2017, p. 135).

6 La Reforma Universitaria fue una revuelta estudiantil de la Universidad Nacional de Córdoba que, entre otras cosas, conquistó el cogobierno universitario en el año 1918. El Cordobazo fue una insurrección obrero-estudiantil contra las medidas represivas y político-económicas del gobierno nacional del año 1969. En el año 1998, ante el cierre de la cervecería sus trabajadores ocuparon el edificio y reclamaron la reapertura. Esta medida de fuerza contó con el apoyo de vecines de Alberdi y barrios aledaños; fue fuertemente reprimida por las fuerzas policiales.

7 Las empresas que se valen de la edificación del espacio urbano para la obtención de ganancias, bajo la idea del "desarrollo urbano", ligadas a la modernización, en Alberdi se autodenominan "desarrollistas urbanos" y se nuclean desde el año 2004 en la Cámara Empresarial de Desarrollistas Urbanos Córdoba (CEDUC). Estos desarrollistas disponen de capital para llevar a cabo proyectos urbanísticos en los cuales la ciudad se presenta como un valor de cambio, un objeto del que se puede obtener una ganancia.

8 En reiteradas oportunidades indicaron que se ocupan de la higiene del predio mediante la contratación de un joven que limpia al finalizar la jornada. Además, expresaron que se comunican entre elles cuando notan algo sospechoso, para solicitar presencia policial con celeridad (C.C.).

9 Creemos importante llamar la atención sobre la doble jornada laboral de les feriantes: una en relación de dependencia y la otra como feriantes (cuentapropista).

10 Estas son algunas ferias que han comenzado a organizarse en los últimos diez años a pocas cuadras de la Isla de los Patos. Los domingos, desde el año 2018, se realiza una pequeña feria a menos de cinco cuadras, en el Paseo del Aguaducho, donde vecines de Alberdi y barrios aledaños generalmente venden comidas, bebidas, ropa, joyas, cosméticos, libros, etc. En el mismo pasaje se desarrolla la Feria Agroecológica los miércoles por la tarde y se ofrecen diferentes productos agroecológicos: frutas, verduras, legumbres, pastas, panificados, entre otros. Siguiendo el curso del Río Suquía en dirección al centro de la ciudad, a menos de tres kilómetros, se monta todos los sábados y domingos, aproximadamente desde el año 2011, la feria de Las Heras, en la que se comercializan ropa nueva y usada, plantas, cosméticos, comidas y otros objetos.

11 Se organizan festejos abiertos a todo público para conmemorar diferentes fechas patrias o significativas del Perú: Día de la Madre (dos veces: en mayo es la fecha peruana y en octubre la argentina), Día del Padre (en junio), la independencia de Perú (en julio), Día del Niño (en agosto), el aniversario de la Feria (en noviembre), Día de la Virgen de la Puerta (en diciembre) y la Navidad (en diciembre, suelen brindar con chocolatada) (C.C. 14/07/2019). Generalmente, realizan sorteos e invitan a grupos musicales que interpretan estilos de aquel país (por ejemplo, «Corazón peruano» el 28 de julio de 2019), y en ocasiones cuentan con la presencia de representantes de su consulado en Córdoba (como en el festejo del Día de la Madre el 19/05/2019). Todo esto, además de la logística, supone una inversión en equipos de sonido, decoración, gastos de les artistas y sorteos.

12 La traducción es nuestra. 